\title{
Development of proglacial lakes and evaluation of related outburst sus- ceptibility at the Adygine ice-debris complex, northern Tien Shan
}

\section{Kristyna Falatkova et al.}

Correspondence to: Kristyna Falatkova (falatkok@natur.cuni.cz)

The copyright of individual parts of the supplement might differ from the CC BY 4.0 License. 


\section{Supplements}

Table S1. Morphometry of lakes at Adygine site. Lakes 3-9 are the most dynamic ones situated near the glacier terminus. A hyphen is used when a measurement was not carried out for the individual lake. Asterisk signifies a value obtained from a satellite image.

\begin{tabular}{|c|c|c|c|c|c|c|c|c|c|c|}
\hline & Lake & 1 & 2 & 3 & 4 & 5 & 6 & 7 & 8 & 9 \\
\hline \multirow{7}{*}{$\begin{array}{c}\text { Area } \\
\left(\mathrm{m}^{2}\right)\end{array}$} & 2005 & - & 32700 & - & - & - & - & - & 0 & 0 \\
\hline & 2007 & 3390 & - & 5710 & 3230 & 3230 & 3350 & 1860 & 0 & 0 \\
\hline & 2008 & - & 31900 & 7030 & 3680 & 1580 & 3410 & 1910 & 0 & 0 \\
\hline & 2012 & - & - & 8800 & 5100 & 740 & 3800 & 1280 & 1130 & 0 \\
\hline & 2013 & - & - & 9870 & 4870 & 0 & 3405 & 0 & 558 & 0 \\
\hline & 2015 & - & 31700 & 14880 & 4540 & 0 & 0 & 0 & 0 & 1540 \\
\hline & 2017 & $2700^{*}$ & $31900 *$ & 16020 & $4200^{*}$ & 0 & $2700 *$ & 0 & 0 & $1150^{*}$ \\
\hline \multirow{6}{*}{$\begin{array}{l}\text { Length } \\
\text { (m) }\end{array}$} & 2007 & 109 & - & 161 & 90 & 120 & 106 & 85 & 0 & 0 \\
\hline & 2008 & - & 364 & 166 & 92 & 94 & 113 & 85 & 0 & 0 \\
\hline & 2012 & - & - & 168 & 105 & 54 & 113 & 65 & 60 & 0 \\
\hline & 2013 & - & - & 174 & 106 & 0 & 113 & 0 & 67 & 0 \\
\hline & 2015 & - & 390 & 198 & 100 & 0 & 0 & 0 & 0 & 70 \\
\hline & 2017 & $110^{*}$ & $390 *$ & 200 & $95^{*}$ & 0 & $90 *$ & 0 & 0 & $50^{*}$ \\
\hline \multirow{6}{*}{$\begin{array}{c}\text { Max } \\
\text { depth } \\
\text { (m) }\end{array}$} & 2005 & - & 21.6 & - & - & - & - & - & 0 & 0 \\
\hline & 2007 & 4.4 & - & 3.8 & - & - & - & - & 0 & 0 \\
\hline & 2008 & - & 22.2 & - & - & - & - & - & 0 & 0 \\
\hline & 2012 & - & - & 10.3 & 2.4 & - & 3 & 0.5 & 1.8 & 0 \\
\hline & 2015 & - & 21.3 & 12.3 & 2.4 & 0 & 0 & 0 & 0 & - \\
\hline & 2017 & - & - & 14 & - & 0 & - & 0 & 0 & - \\
\hline \multirow{6}{*}{$\begin{array}{c}\text { Volume } \\
\left(\mathbf{m}^{3}\right)\end{array}$} & 2005 & - & 208000 & - & - & - & - & - & 0 & 0 \\
\hline & 2007 & 6290 & - & 7800 & - & - & - & - & 0 & 0 \\
\hline & 2008 & - & 206000 & - & - & - & - & - & 0 & 0 \\
\hline & 2012 & - & - & 29300 & 3900 & - & 3800 & 500 & 900 & 0 \\
\hline & 2015 & - & 194000 & 72000 & 3630 & 0 & 0 & 0 & 0 & - \\
\hline & 2017 & - & - & 106000 & - & 0 & - & 0 & 0 & - \\
\hline
\end{tabular}




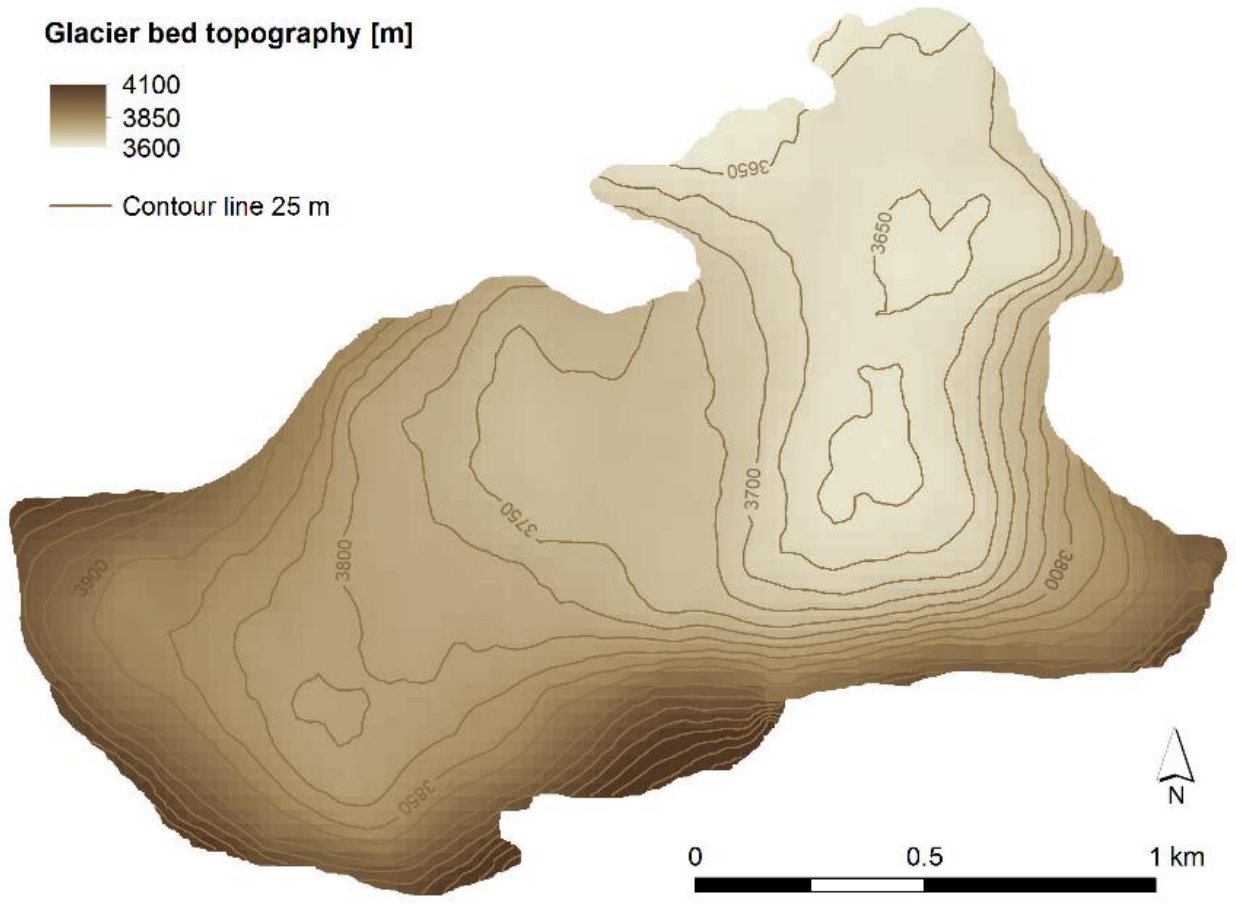

Figure S2. Adygine glacier bed topography derived from the GPR survey in 2012. 